Article

\title{
Evaluation of Mechanical Properties of Concrete Reinforced with Eucalyptus globulus Bark Fibres
}

\author{
Claudia Mansilla ${ }^{1}$, Mauricio Pradena ${ }^{1,2, *}$, Cecilia Fuentealba ${ }^{2}$ and Andrés César ${ }^{1}$ (D) \\ 1 Departamento de Ingeniería Civil, Universidad de Concepción, Edmundo Larenas 219, \\ Casilla 160-C Correo3, Concepción 4030000, Chile; clmansilla@udec.cl (C.M.); acesar@udec.cl (A.C.) \\ 2 Unidad de Desarrollo Tecnológico, UDT, Universidad de Concepción, Casilla 4051, \\ Concepción 4030000, Chile; c.fuentealba@udt.cl \\ * Correspondence: mpradena@udec.cl
}

Received: 14 September 2020; Accepted: 12 November 2020; Published: 1 December 2020

\begin{abstract}
Concrete is a material with high compressive strength, but predisposed to shrinkage cracking, rapid cracks propagation, and brittle failures. The incorporation of fibre is an acceptable solution to reduce these limitations. However, high cost and energy consumption related to man-made fibres have placed natural fibres as an attractive sustainable alternative, especially considering that different natural fibres are industrial waste (as the Eucalyptus globulus bark fibre). Still, natural fibres can produce an important reduction of concrete strength. Hence, the objective of this study is to evaluate the effects of Eucalyptus globulus bark fibre in traditional concrete mechanical properties as compressive and flexural strength. For this, an experimental program was developed in such a way that reduces the results uncertainties and increases the power of decision regarding the percentage and fibre conditions of the samples. The results indicate that, unlike other natural fibres, the traditional mechanical properties have a slight reduction and acceptable workability. This fact is more evident in the samples with $0.50 \%$ fibre with respect to the weight of cement. Therefore, reinforcing mortars and concrete with Eucalyptus globulus bark fibres emerges as an eco-friendly building alternative to reuse this industrial waste.
\end{abstract}

Keywords: compressive strength; Eucalyptus globulus; flexural strength; mechanical properties; natural fibre; reinforced concrete; sustainability

\section{Introduction}

Globally, concrete is one of the most used materials in the construction industry, with an estimating production of 30 billion tons per year [1].

Despite being a material known for its high compressive strength [2], the concrete material is predisposed to shrinkage cracking, rapid cracks propagation, and brittle failures [3,4]. In this context, the addition of fibres in the concrete mixture has proven to be an acceptable solution to minimize these limitations [5-7]. In effect, fibres improve the post-cracking behaviour and the residual strength of concrete, which is important for the overall performance of concrete members under monotonic and cyclic loading [8-10]. Fibres are a promising non-conventional reinforcement in concrete elements because they alters the brittle failures to ductile (pseudo-ductile) ones, improving the deformation capability, reducing cracking and presenting higher energy dissipation regarding to the non-fibrous elements [11-14]. Fibres can also contribute to minimize the corrosion problems in concrete structures, because fibres limit the formation and cracking increment, and they can replace part of the steel reinforcement [10,15].

The fibres consist of thin and short filaments that are randomly distributed throughout the structure [16,17]. According to their composition they are classified as steel, glass, synthetic or natural 
fibres [18]. However, the vulnerability of steel to corrosion and the high cost and energy in the manufacture of synthetic fibres have placed natural fibres as an attractive reinforcement alternative [19]. In addition, man-made fibres are non-biodegradable, and when they are disposed of in landfills, they can cause pollution by releasing heavy metals and other pollutants into the ground water as well as in the soil [20,21].

Natural fibres as reinforcement material have been used in construction since the early 19th century [22]. Between the applications of concrete with natural fibres reinforcement is possible to find the construction of pipes, silos, slabs on grade, airports and pavements, tunnelling, rock stability, shotcrete, and others [23-25].

Compared to man-made fibres (steel, glass and synthetic), natural fibres are less expensive, locally abundant (sometimes as a waste), renewable, lightweight and biodegradable [26-30]. Moreover, natural fibres have very low embodied energy [31], i.e., sum total of the energy used at each step of the process needed to create a particular finished product. The carbon footprints as well as the embodied energy of natural fibres are very low as compared to artificial ones [32]. Furthermore, the health and safety concerns during their handling, processing, and mixing are less [33]. Therefore, from a sustainable perspective, natural fibres are postulated as a promising reinforcement material for concrete using natural assets and with a non-hazardous impact on the environment [33-35]. This is especially relevant in the construction industry, which is responsible for a large amount of non-renewable resources and (only in Europe) of 30\% of the emission of carbon dioxide gases [15].

In addition, studies conducted by Soto, Ramalho and Izquierdo [36], and Okeola, Abuodha and Mwero [37] report that sisal fibres limited the cracks propagation in the reinforced concrete. In fact, fibre addition is an accepted technique for controlling shrinkage cracking, which is a cause of premature deterioration [38].

Llerena [39] identified that the increase in the ductility of the compound is due to the vegetable fibre.

Sen and Reddy [40] compared the effectiveness of green retrofitting schemes made of sisal Fibre Reinforced Polymer (FRP) with schemes of carbon FRP and glass FRP in reinforced concrete beams. The failure mode performance of sisal FRP was similar to the ones of carbon FRP and glass FRP. Moreover, sisal FRP promoted ductile failure of beams with sufficient warnings unlike carbon FRP and Glass FRP, which underwent sudden debonding.

Ribeiro et al. [41] identified the high water retention and reduction of surface temperature as a countermeasure for urban heat islands when natural bagasse fibres are incorporated in concrete blocks for pavements.

However, the incorporation of natural fibre can produce a significant reduction in the concrete compressive strength. There is more reduction as the amount of fibres increase [42]. For example, Yalley and Kwan [43] studied the mechanical performance of coconut fibre reinforced concrete with $0.25 \%, 0.50 \%$ and $0.75 \%$ with respect to the weight of the cement. Compared to the control samples (without fibre), the results show a decrease in compressive strength between $11 \%$ and $33 \%$.

Similarly, Zakaria et al. [35] report that incorporating $0.75 \%, 1.75 \%$, and $3.52 \%$ of jute fibre, with respect to the weight of cement, reduces the compression strength between approximately $6 \%$ and $35 \%$. Moreover, Okeola et al. [37] mentioned that adding sisal fibre in $0.5 \%, 1.0 \%, 1.5 \%$, and $2.0 \%$ with respect to the weight of cement, causes a compressive strength reduction by $4.22 \%, 11.54 \%, 18.18 \%$, and $25.30 \%$, respectively. Finally, the study performed by Yursa et al. [44] shows that the addition of concrete with bamboo fibres in $0.5 \%, 1.0 \%$, and $1.5 \%$ of the weight of cement decrease the compressive strength in $1.67 \%, 5.44 \%$, and $12.00 \%$, respectively.

As concrete strength, especially compressive strength, is a fundamental characteristic related with the massive use of this material, the incorporation of waste into the concrete, requires a strength evaluation of the concrete-waste composite. In fact, that incorporation can generate different technical benefits, but if the strength of the concrete-waste composite is significantly less than the reference concrete, the practical possibilities to be massively used in different concrete applications can be very limited. However, from a sustainable point of view, it is important to produce a composite 
concrete-waste that effectively has practical possibilities to be applied. For that reason, the strength evaluation of that composite is fundamental. This is even more evident when the waste is natural fibres because different authors report a reduction of the compressive strength as the amount of fibres increases $[35,37,42-44]$. Then, being the amount of fibres to incorporate in the concrete limited to a small quantity, a significant reuse of waste fibres will be related with the massive use of concrete, which will depend of the strength of the concrete-fibre composite. That is an important reason why several studies have focused on evaluating the performance of mixes with different natural fibre dosages. The final goal of that process is to determine optimal proportions to be incorporated into the concrete [45-48]. Those proportions will be related, between other factors, with the particular fibre under study, the treatment applied during its incorporation and the uniformity of volume distribution of the fibre in the mix $[29,49]$. The present article focuses in the application of natural fibres produced with bark of Eucalyptus globulus (E. globulus). In Chile, E. globulus has a relevant role as one of the most used tree species in the forestry industry $[50,51]$. In particular, at the Biobio region, which concentrates forest plantations, 4.2 billion of wood are consumed per year [51]. This generates bark corresponding to $9.2 \%$ of the total volume of the tree [52] and represents approximately 386 thousand $\mathrm{m} 3$ of annual bark. This is not an isolated case. In fact, Eucalyptus plantations cover large areas around the world (>20 million hectares) in countries, such as Australia, Spain, Portugal, Kenya, Brazil, Uruguay, and Chile [53]. Therefore, the disposal and reuse of Eucalyptus bark is a problem in different countries and regions. In effect, the bark is the external protection of the tree and it needs to be extracted before the wood can be commercially used. In this way, the bark is an industrial waste. In particular, at the Biobio region in Chile, part of the E. globulus bark waste generated is used to produce energy. However, compared to other biomass products, the process is inefficient due to its fibrous structure, low heating value and higher ash content [54]. Therefore, it is necessary to develop alternatives that contribute to the reuse of waste.

Although there have been several studies related to concrete reinforcement with natural fibres of different origins $[36,37,45-48,55]$, to the best of the authors' knowledge, there is a lack of research considering fibres from the bark of the species E. globulus, and its impact on concrete performance. This is an important fact, because bark is distinctive of a tree, and even they are different between Eucalyptus species. Actually, bark is an important element of tree identification [56]. Furthermore, as bark protects the tree from the environment where it is located, the bark characteristics are geo-dependent as well.

Geo-dependency is fundamental when dealing with waste materials and concrete, especially because the alternatives of solutions must be practical and possible to apply. This, from a sustainable perspective, will allow to effectively reuse the industrial waste. Actually, geo-dependency is one of the characteristics of the concrete material that make it so popular, as it is possible to use local raw materials.

The work presented in this article is part of a bigger investigation about the effect of E. globulus bark fibres as concrete reinforcement. However, for the reasons explained before, it is fundamental to know if the bark fibre of E. globulus significantly reduces the strength of the composite concrete-waste. Hence, the objective of the present article is to evaluate traditional mechanical properties of concrete reinforced with E. globulus bark fibres. This is especially relevant considering that natural fibres are known for producing a significant reduction of the concrete strength.

In this way, for the particular case of E. globulus bark fibres, the article includes the evaluation of the influence of different fibre proportions and fibre treatments on the compressive and flexural strength of the composite concrete-waste.

Additionally, a preliminary evaluation of the durability of the fibres in the concrete is made, considering that the durability of the mixes could eventually be affected by volumetric changes of the fibres due to their high-water absorption capacity and their potential weakness against the alkalinity of the cementitious matrix [57-59]. 


\section{Materials and Methods}

\subsection{Materials}

\subsubsection{Cement}

Cement from two different suppliers typically used by the construction industry in Chile were considered in the research. This choice was based on the importance of developing practical sustainable alternatives towards reusing industrial waste. Based on the Chilean standard NCh 148 [60], both are classified as standard grade Portland pozzolanic cement (max. 30\% pozzolanic). The properties of the cements used in the study are presented in Table 1.

Table 1. Cement characterization.

\begin{tabular}{cccc}
\hline Properties & Cement 1 (C1) & Cement 2 (C2) & Requirements \\
\hline Autoclave expansion (\%) & 0.1 & 0.1 & 1.0 max. \\
Initial setting (h:m) & $02: 40$ & $01: 30$ & $01: 00$ min. \\
Final setting (h:m) & $03: 40$ & $05: 50$ & $12: 00$ max. \\
Compressive strength $(\mathrm{kg} / \mathrm{cm} 2)$ & & & \\
3 days & 270 & & \\
7 days & 320 & 187 & $180 \mathrm{~min}$ \\
28 days & 410 & 275 & $250 \mathrm{~min}$ \\
\hline
\end{tabular}

\subsubsection{Aggregates}

Table 2 presents the properties of the fine and coarse aggregate ( $20 \mathrm{~mm}$ maximum size) used in the samples. Both aggregates satisfy the minimum requirements for the production of mortars and concrete [61].

Table 2. Physical properties of fine and coarse aggregates.

\begin{tabular}{ccc}
\hline Physical Properties & Fine Aggregate & Coarse Aggregate \\
\hline Loose bulk density $\left(\mathrm{kg} / \mathrm{m}^{3}\right)$ & 1.57 & 1.49 \\
Bulk density consolidated $\left(\mathrm{kg} / \mathrm{m}^{3}\right)$ & 1.66 & 1.63 \\
Relative density dry $\left(\mathrm{kg} / \mathrm{m}^{3}\right)$ & 2.66 & 2.67 \\
Absorption $(\%)$ & 2.05 & 1.05 \\
Percentage of compacted Voids $(\%)$ & 40.98 & 44.0 \\
Materials finer than the No. 200 sieve $(\%)$ & 0.2 & 0.6 \\
Fineness Modulus & 3.12 & 6.67 \\
Organic Impurities & No & - \\
\hline
\end{tabular}

\subsubsection{Eucalyptus globulus Bark Fibre}

The E. globulus bark fibres were provided by the Unidad de Desarrollo Tecnológico, UDT (Technological Development Unit) of the Universidad de Concepción, Chile (Figure 1). The fibre is characterized by having a light brown colour (Figure 1), absorption of 350\%, length between $10 \mathrm{~mm}$ and $20 \mathrm{~mm}$, and $2 \mathrm{~mm}$ average thickness. The chemical composition is presented in Table 3. Previously, the fibres were screened in order to use only material retained in $3 / 8^{\prime \prime}$ sieve. 


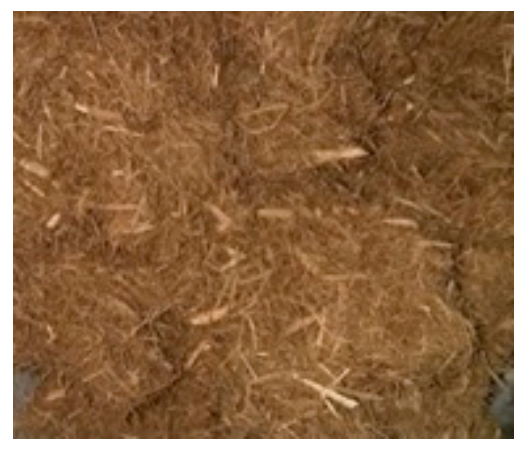

Figure 1. Eucalyptus globulus bark fibre.

Table 3. Chemical composition of E. globulus bark fibre.

\begin{tabular}{cc}
\hline Component & \% Dry Solid Base \\
\hline Ethanol/Water Extractives & $7.43 \pm 0.03$ \\
Cellulose & $49.91 \pm 2.56$ \\
Hemicellulose & $18.12 \pm 4.16$ \\
Klason Lignin & $17.60 \pm 0.49$ \\
Ash & $7.62 \pm 0.32$ \\
Absorption $(\%)$ & 350 \\
\hline
\end{tabular}

\subsection{Experimental Program}

In order to increase the information possible to obtain from the samples behaviour, the experimental program was divided into three consecutive stages (Figure 2). This strategy was chosen to narrow the range of study based on the results obtained in the previous phase. In this way, stage 1 considers the evaluation with two cements and high percentages of bark fibre (2\% and 5\%). According to the results obtained in stage 1 , the cement with the best performance is chosen for the next phases. In a similar way, decisions are taken regarding to the percentage of bark fibre based on the results of the previous phases. Then, at stage 3, only the percentage of fibre with the best results at stage 2 is evaluated.

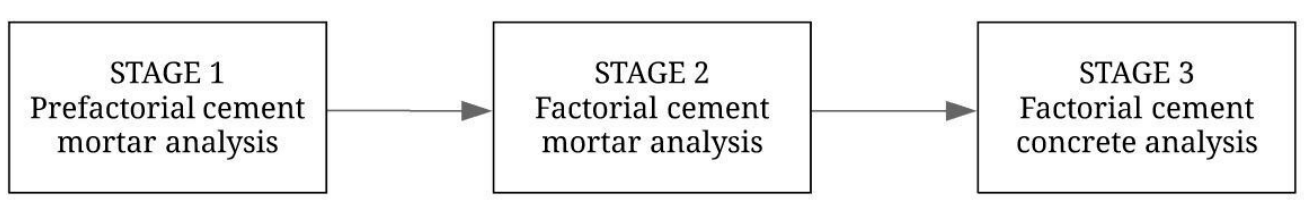

Figure 2. Experimental program with three consecutive stages.

To study the potential influence of the high absorption of the fibre in the cement mortar and concrete behaviour, the fibres are included in dry and saturated state. Moreover, to evaluate potential durability effects, at stage 2 the fibres are treated with a paraffinic emulsion and the $\mathrm{pH}$ of the cementitious matrix is measured.

Figure 3 presents the details of the first stage. This phase consists of a pre-factorial analysis of cement mortars. The tests were performed on specimens with dimensions of $40 \times 40 \times 160 \mathrm{~mm}$ according to the Réunion Internationale des Laboratoires et Experts des Matériaux, systèmes de construction et ouvrages (RILEM) (Figure 3) [62]. The samples were made with both type of cements, estimating a compressive strength of $41 \mathrm{MPa}$ and slump between $3 \mathrm{~cm}$ and $8 \mathrm{~cm}$. These target values were chosen based on the importance of developing practical alternatives towards effectively reusing industrial waste. The amount of added fibre was $0 \%$ (control sample), $2 \%$, and $5 \%$ with respect to the weight of cement. In addition, the fibres were incorporated in a dry and saturated state. 


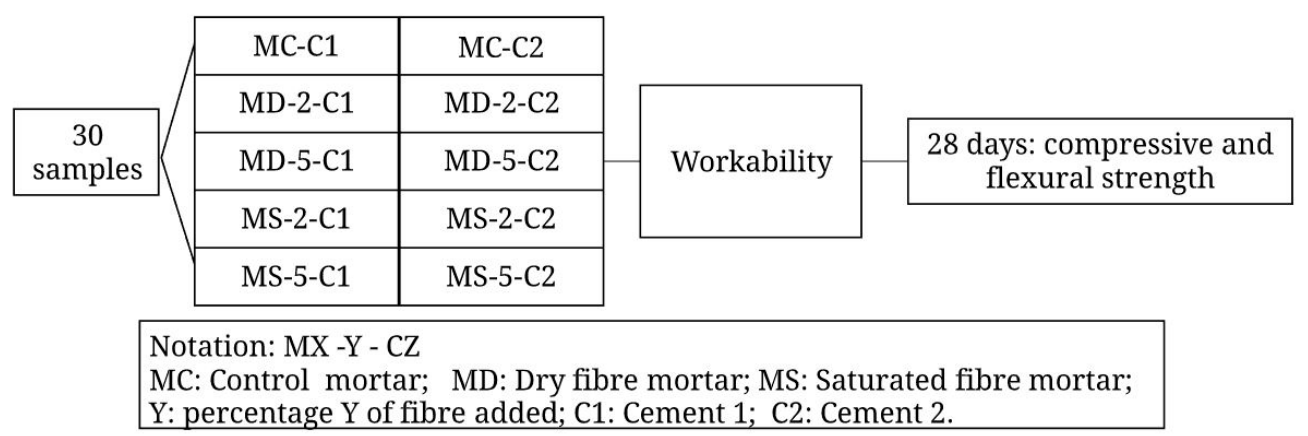

Figure 3. Work plan description of stage 1.

In the preparation, the consistency of all samples was evaluated by means of the reduced Abrams cone slump method, according to NCh 2257/3 [63]. The compressive and flexural strength at 28 days was evaluated in accordance with the American Society for Testing and Materials standard ASTM C 270 [64], using multi-test equipment SERCOMP 7 controls.

Figure 4 presents the details of the second stage. This phase consists in a factorial analysis of cement mortars RILEM specimens made with cement 1 . The compressive strength and slump projected in the design are the same as in stage 1 . The fibre was added in proportions of $0 \%$ (control sample), $0.5 \%$, and $1.0 \%$ in relation to the weight of cement. In addition, the fibre was added in a dry, saturated state, and treated with a paraffinic emulsion composed of $10 \%$ paraffin and $90 \%$ water. This last case was included to evaluate the potential effects on the fibres durability. In effect, the modification of the fibre surfaces with physical or chemical agents is a mitigation strategy to protect them against the potential degradation caused by the alkaline environment of the cementitious matrix.

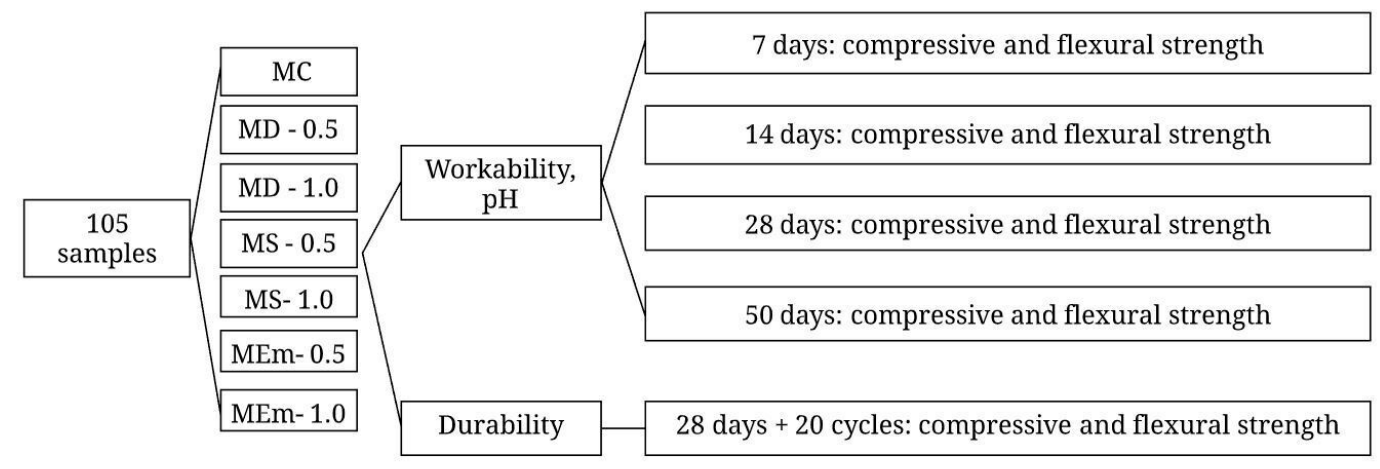

Notation: MX -Y

MC: Control mortar; MD: Dry fibre mortar; MS: Saturated fibre mortar; ME: Mortar treated with paraffin emmulsion Y: percentage Y of fibre added

Figure 4. Work plan description of stage 2.

In fresh state, the consistency of the cement mortars samples was evaluated according to NCh 2257/3 [63] and the $\mathrm{pH}$ values recorded with a Hanna $\mathrm{pH}-$ meter model $\mathrm{pH} 21$. This allows monitoring the alkalinity levels of the cementitious matrix while evaluating the performance of the fibre reinforced mortars.

Similar to stage 1 , the compressive and flexural strength of the samples was evaluated, but in this phase not only at 28 days, but also at 7, 14, and 50 days according to ASTM C 270 [64].

For the evaluation of durability, an accelerated aging process was carried out once the samples had completed 28 days of curing. The test is based on the application of 20 cycles of $24 \mathrm{~h}$. Each cycle consists of $18 \mathrm{~h}$ of oven heating at $105 \pm 5^{\circ} \mathrm{C}$ followed by $6 \mathrm{~h}$ of immersion in water at $20^{\circ} \mathrm{C}$. At the end of the 20 cycles, flexural and compression strength tests were performed $[65,66]$. 
Figure 5 presents the details of the third stage. This phase consists of the factorial analysis of concrete cubic samples $(200 \mathrm{~mm})$ and beam samples $(150 \times 150 \times 530 \mathrm{~mm})$. Cement 1 was used in the preparation, estimating a compressive strength of $43.5 \mathrm{MPa}$ and slump between 5 and $7.5 \mathrm{~cm}$. The fibres were incorporated in a dry and saturated state. The fibre dosages considered were $0 \%$ (control sample) and $0.5 \%$ in relation to cement weight.

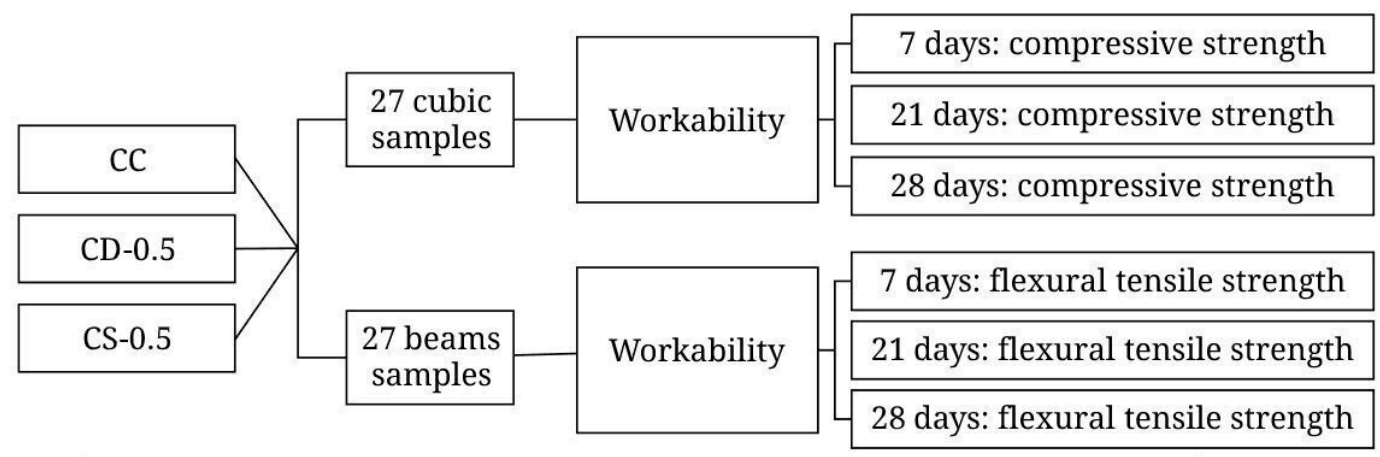

Notation: MX -Y
CC: Control concrete; CD: Dry fibre concrete; CS: Saturated fibre concrete;
Y: percentage Y of fibre added

Figure 5. Work plan description stage 3.

In the preparation, the consistency of all samples was evaluated by means of the Abrams cone slump method according to ASTM C143/C143M [67]. At this stage, docility, compressive and flexural strength were evaluated at ages 7, 21, and 28 days, according to ASTM C94/C94M [68].

\subsection{Samples Mix Dosage}

Table 4 presents the dosage of the cement mortar samples evaluated in the factorial phase. The cement mortar mixes were designed following the design principles presented by the Chilean Highway Agency [61] and Egaña [69].

Table 4. Cement mortar mix dosage.

\begin{tabular}{ccccccccc}
\hline & \multicolumn{4}{c}{ Cement 1 } & \multicolumn{4}{c}{ Cement 2 } \\
\hline \% Fibre & $\mathbf{0}$ & $\mathbf{0 . 5}$ & $\mathbf{1}$ & $\mathbf{2}$ & $\mathbf{5}$ & $\mathbf{0}$ & $\mathbf{2}$ & $\mathbf{5}$ \\
\hline Cement (kg) & 559.6 & 559.6 & 559.6 & 559.6 & 559.6 & 506.9 & 506.9 & 506.9 \\
Water (L) & 223.8 & 223.8 & 223.8 & 223.8 & 223.8 & 263.6 & 263.6 & 263.6 \\
Fine Aggregate (kg) & 1488.6 & 1485.8 & 1455 & 1449.4 & 1460.6 & 1409.3 & 1388.2 & 1384 \\
Fibre (kg) & 0 & 2.8 & 5.6 & 11.2 & 28 & 0 & 10.1 & 25.3 \\
\hline
\end{tabular}

Concrete mixtures were designed based on the American Concrete Institute (ACI) method [70]. Table 5 presents the mix designs for the fibre conditions evaluated $(0 \%$ and $0.5 \%)$.

Table 5. Concrete mix dosage.

\begin{tabular}{ccc}
\hline \% Fibre & $\mathbf{0}$ & $\mathbf{0 . 5}$ \\
\hline Cement $(\mathrm{kg})$ & 436.8 & 436.8 \\
Water $(\mathrm{L})$ & 190 & 190 \\
Fine aggregate $(\mathrm{kg})$ & 793.9 & 746.6 \\
Coarse aggregate $(\mathrm{kg})$ & 945.4 & 945.4 \\
Fibre $(\mathrm{kg})$ & 0 & 2.2 \\
\hline
\end{tabular}




\section{Results}

\subsection{Stage 1: Cement Mortar Pre-Factorial}

\subsubsection{Fresh State Behaviour}

Table 6 presents the consistency results of the fresh mixes contained by the reduced Abrams cone slump method [63].

Table 6. Consistency results of the pre-factorial cement mortar mixes.

\begin{tabular}{cc}
\hline Mortar Mix & Slump (cm) \\
\hline MC-C1 & 4.5 \\
MC-C2 & 4.1 \\
MD-2-C1 & 3.4 \\
MD-2-C2 & 2.9 \\
MD-5-C1 & 1.5 \\
MD-5-C2 & 1.0 \\
MS-2-C1 & 4.0 \\
MS-2-C2 & 3.0 \\
MS-5-C1 & 2.5 \\
MS-5-C2 & 2.0 \\
\hline
\end{tabular}

The results of Table 6 show that as the amount of fibre increases the workability of the mixes decreases. In fact, regardless of the type of cement or the condition of the fibre (dry or saturated), the mixes with $5 \%$ fibre were the lowest slump values. In comparison, the mixes with $2 \%$ bark fibre presents higher slump values, but always lower than the control samples. Other investigations have found similar results, i.e., as the amount of fibre increases, a reduction of workability is produced [35,37].

In addition, it is observed that mixes with saturated fibres have slightly higher slump values than the ones with dry fibres. This can be explained by the fact that, in saturated condition, the fibres are unable to absorb water. On the contrary, as dry fibres absorb water, there is less water in the mix, which affects the workability.

\subsubsection{Compressive Strength}

Figure 6 presents the results of the samples compressive strength with their standard error. Control samples show the best results.
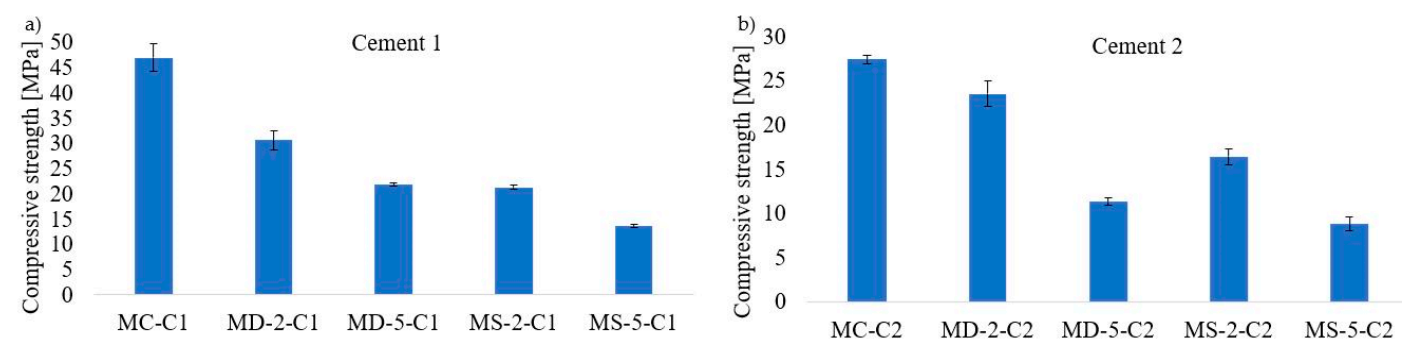

Figure 6. Pre-factorial cement mortar results, compressive strength: (a) Cement 1; (b) Cement 2.

Compared to samples with $5 \%$ fibre, the results indicate that the addition of $2 \%$ fibre in dry and saturated state causes less compressive strength loss. However, in both cases, the strength reduction is significant. This behaviour agrees with the results found by other researchers working with incorporation of natural fibres into the concrete $[35,37,42,43]$. The strength reduction can be associated to the workability reduction, understanding that compaction is more difficult and the voids presence increases $[37,43]$. This situation can be clearer in the case of $5 \%$ fibre, considering the amount of workability reduction presented in Section 3.1.1. This high amount of fibres introduced in the cement 
mortar, and the associated workability reduction, can also produce fibres concentration due to the lack of dispersion (Figure 7). The result is a heterogeneous composite material with weak spots [35].
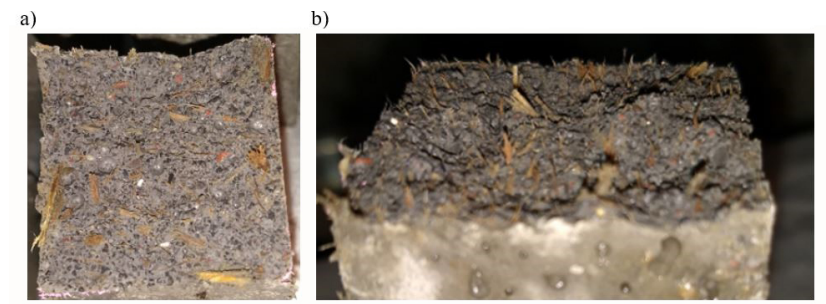

Figure 7. Cement mortar samples with 5\% E. globulus bark fibres: (a) top view; (b) side view.

When comparing the effect of the type of cement, it is observed that the greatest compressive strength is obtained with Cement 1.

\subsubsection{Flexural Strength}

Figure 8 shows that in all cases the flexural strength decreases as the fibre content increases. In fact, for both types of cements, the best result among fibre samples is for the case with $2 \%$ dry fibre. In this case, the flexural strength achieved is $89 \%$ and $98 \%$ of the control samples strength. However, when comparing the effect of the cement used, it is observed that the strength values are higher for Cement 1 .
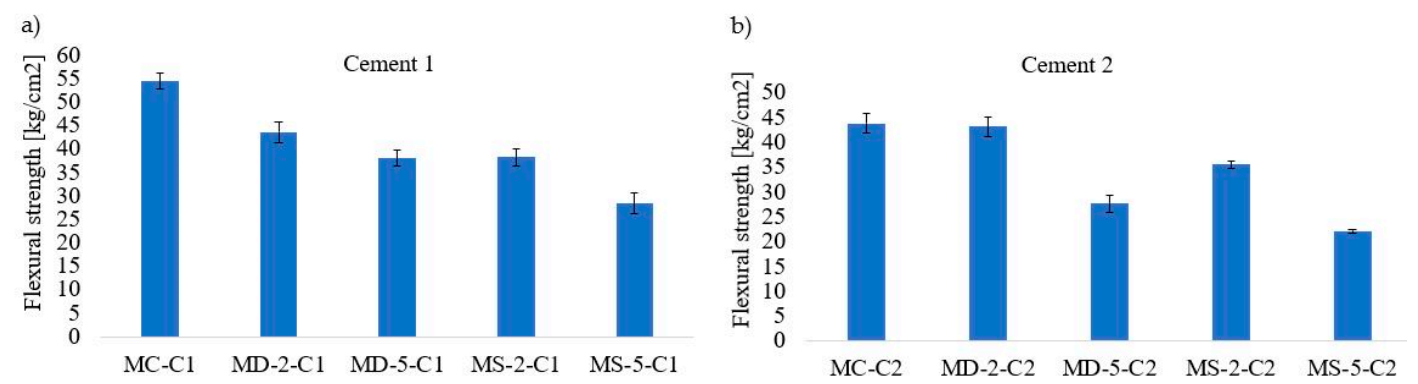

Figure 8. Pre-factorial cement mortar results, flexural strength: (a) Cement 1; (b) Cement 2.

The results showed similar trends to those reported by other researchers, in the sense that the mechanical strength decreases as the fibre content increases $[35,37,43]$. The possible explanations behind this phenomenon are basically the ones presented in Section 3.1.2, with the addition of the bonding between fibre and the cementitious matrix. In effect, bonding between these two materials can be important for the nature of the flexural mechanism. Momoh and Osofero [71] attributes as well this factor with the concrete flexural strength reduction due to the incorporation of oil palm broom fibres. Since all samples made with Cement 2 show results below the target strength, it was decided not use this cement in the following phases. Additionally, considering that the incorporation of $5 \%$ fibres produces significant strength reduction and the best performance were obtained by adding $2 \%$ of fibre, it was decided to evaluate at the second phase lower fibre contents than $2 \%$.

\subsection{Stage 2: Cement Mortar Factorial}

\subsubsection{Fresh State Behaviour}

Table 7 presents the slump, by means of the reduced Abrams cone [63], and the $\mathrm{pH}$ values. 
Table 7. Cement mortal factorial, consistency, and $\mathrm{pH}$ of the mixes.

\begin{tabular}{ccc}
\hline Mortar Mix & Slump (cm) & pH Values \\
\hline MC & 4.1 & 12.9 \\
MD-0.5 & 3.0 & 12.8 \\
MD-1.0 & 3.0 & 12.9 \\
MS-0.5 & 3.0 & 12.7 \\
MS-1.0 & 3.0 & 12.8 \\
MEm-0.5 & 3.5 & 12.4 \\
MEm-1.0 & 3.0 & 12.0 \\
\hline
\end{tabular}

The results indicate that for all cases the inclusion of fibre slightly reduces the mix docility. However, the $1 \mathrm{~cm}$ slump reduction is relatively constant, slight, and cannot be necessarily attributed to an increment or state of the added fibre [72].

When comparing the $\mathrm{pH}$ measurements with the control sample, it is observed that in all cases the $\mathrm{pH}$ decreases. However, these reductions are small being the standard deviation 0.67 . Hence, it is possible to conclude that no significant changes in the concrete alkalinity are produced between samples with and without fibres.

\subsubsection{Compressive Strength}

Figure 9 shows the average compressive strength of the tested samples at the factorial phase.

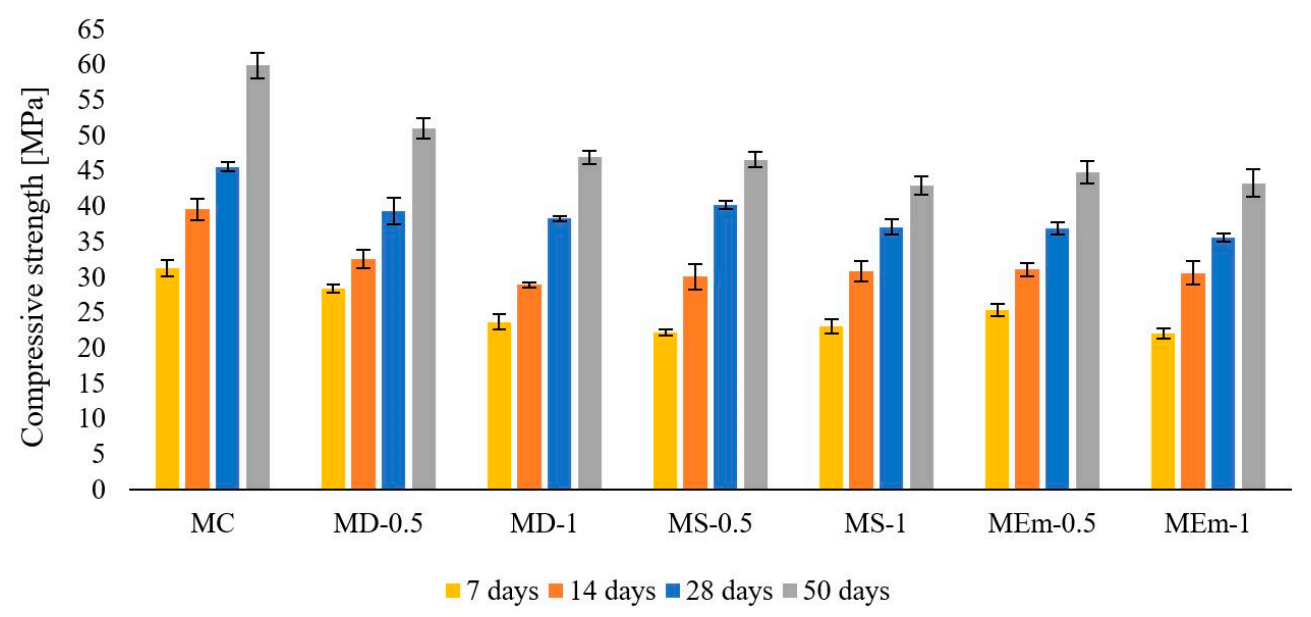

Figure 9. Cement mortar factorial results, compressive strength.

Figure 9 shows that for all ages, the greatest strength was obtained with the control sample. Regarding fibre samples, the best results at 28 days are obtained for the MS- 0.5 sample, obtaining $88 \%$ of the control sample strength. This result is followed by the MD- 0.5 sample with $86 \%$. The lowest result is the MEm-1 sample with $77 \%$.

At 50 days, the best performance is presented by the MD- 0.5 sample, which reaches $85 \%$ of the control sample strength. The MS-1 and MEm- 1 samples show the lowest results with $72 \%$.

Comparing the results of samples with incorporated fibre, the addition of $0.5 \%$ fibre gives better compression strength results than $1 \%$. This fact is maintained regardless of the fibre treatment.

The better results obtained in this phase in comparison to the pre-factorial stage can be attributed to the fact that less amount of fibres reduces the possibility of fibre concentration (Figure 10) and production of weak spots [35]. 


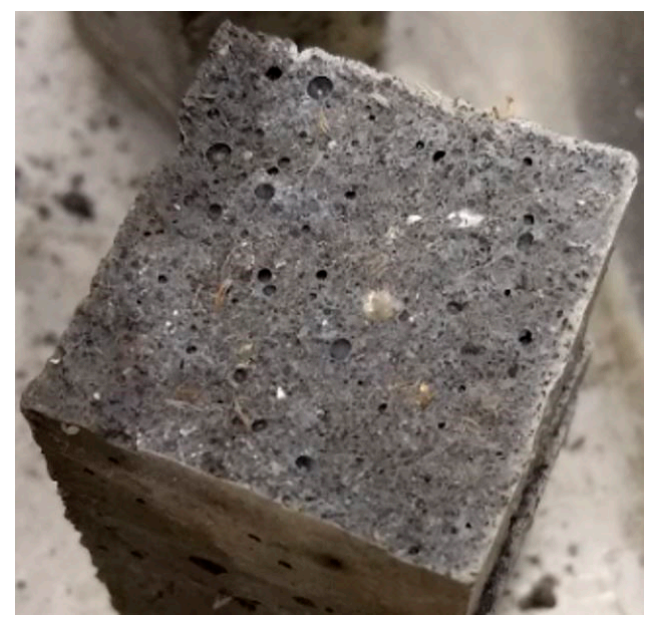

Figure 10. Cement mortar samples with $0.5 \%$ E. globulus bark fibres.

\subsubsection{Flexural Strength}

Figure 11 shows the average flexural strength at ages 7, 14, 28, and 50 days. At 28 days, the fibre samples with the best performance are MD-05 and MS-1. They reached $90 \%$ of the control sample strength. The lowest results were obtained by MEm-1, with $73 \%$ of the control sample strength.

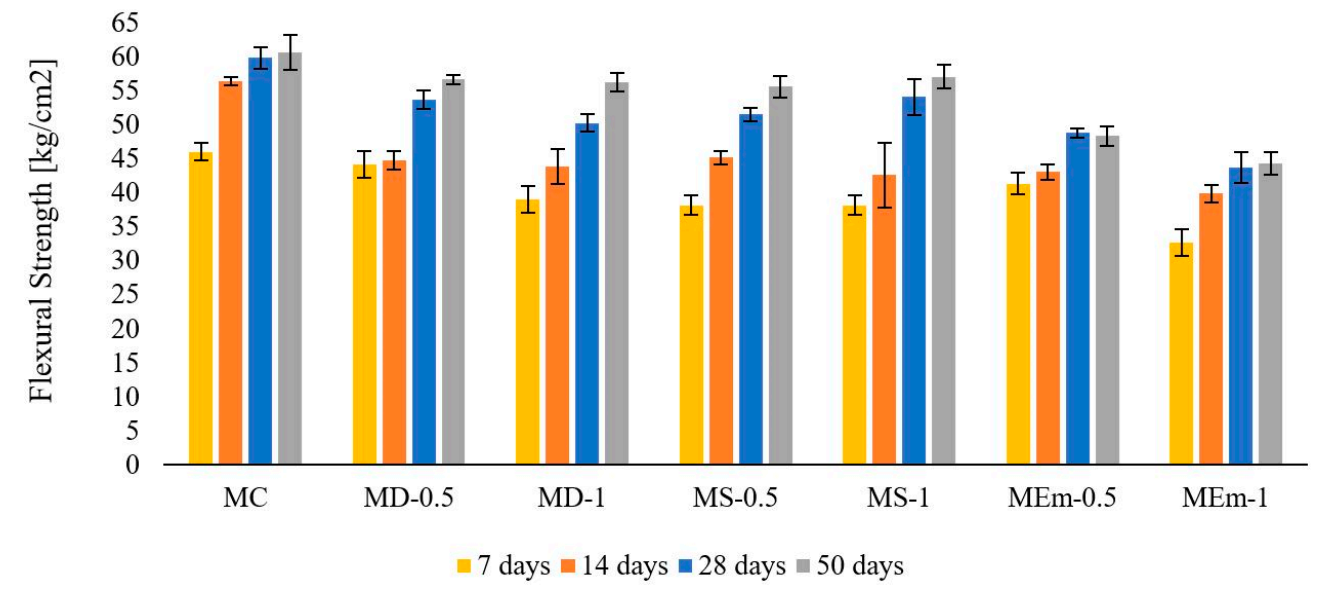

Figure 11. Cement mortar factorial results, flexural strength.

At 50 days, the fibre sample with the best performance was the MS- 1 with $94 \%$ of the control sample strength. This result is slightly higher than the ones obtained by samples MD-0.5 and MD-1 with $93 \%$ and MS- 0.5 with $92 \%$ of the control sample strength respectively. Again, the samples with fibres treated with paraffin emulsion presented the lowest strength regarding to the control samples, with $73 \%$ and $80 \%$ for MEm- 1 and MEm-0.5, respectively.

The flexural strength reached by samples with $0.5 \%$ and $1.0 \%$ is very close to the control samples, especially for the cases highlighted before. Furthermore, the results at 50 days indicate that the fibre samples keep winning strength reducing the gap with the control samples. This fact suggest that the samples with bark fibre can have a later strength development that is worthy to further investigations.

Similar to what was expressed in Section 3.2.2, the better results obtained in this phase with respect to stage 1 can be attributed to the less amount of fibres, which reduces the possibility of fibre concentration (Figure 10) and production of weak spots [35].

There are no significant differences in adding the fibres in dry or saturated state. Therefore, it is not essential to dry the fibre before adding it to the mixture. With respect to the fibres treated with paraffin emulsion, similar to the compressive behaviour, there are no strength advantages related with their application. 


\subsubsection{Durability}

As mentioned before, a preliminary evaluation of the fibres durability in the cementitious matrix is made though accelerated aging process. Figure 12 presents the compressive strength results of the samples after that process. As only slight variations are produced in all cases, it can be concluded that the aging process does not affect the compressive strength.

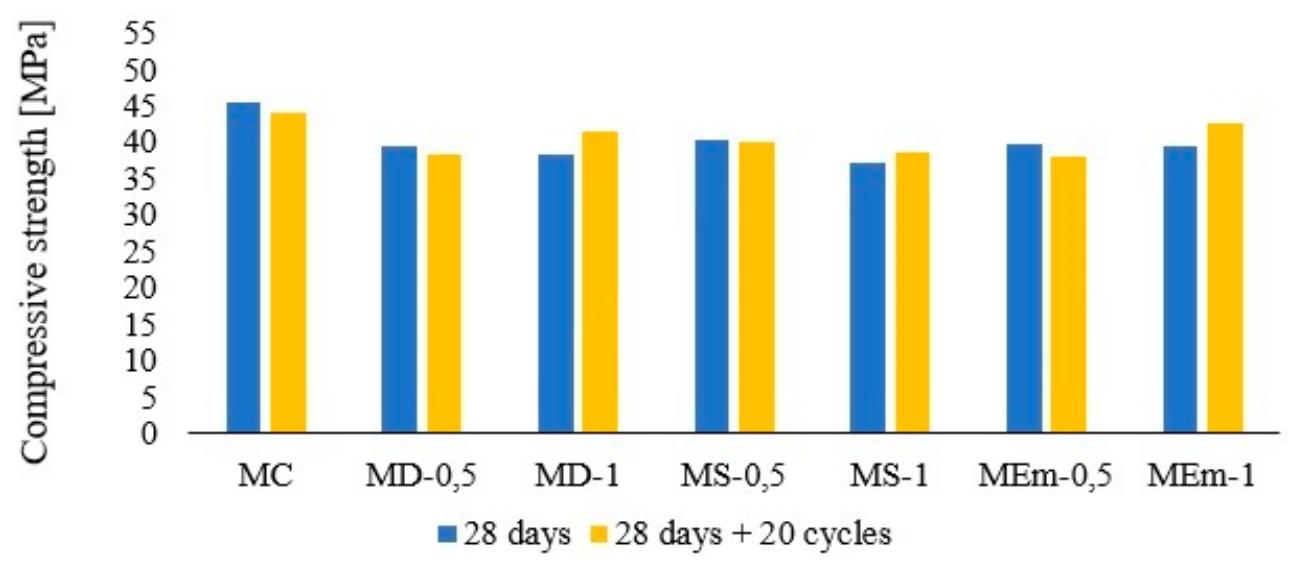

Figure 12. Cement mortar factorial results, compressive strength of aged samples.

In a similar way, Figure 13 presents the flexural strength results at 28 days after the aging process.

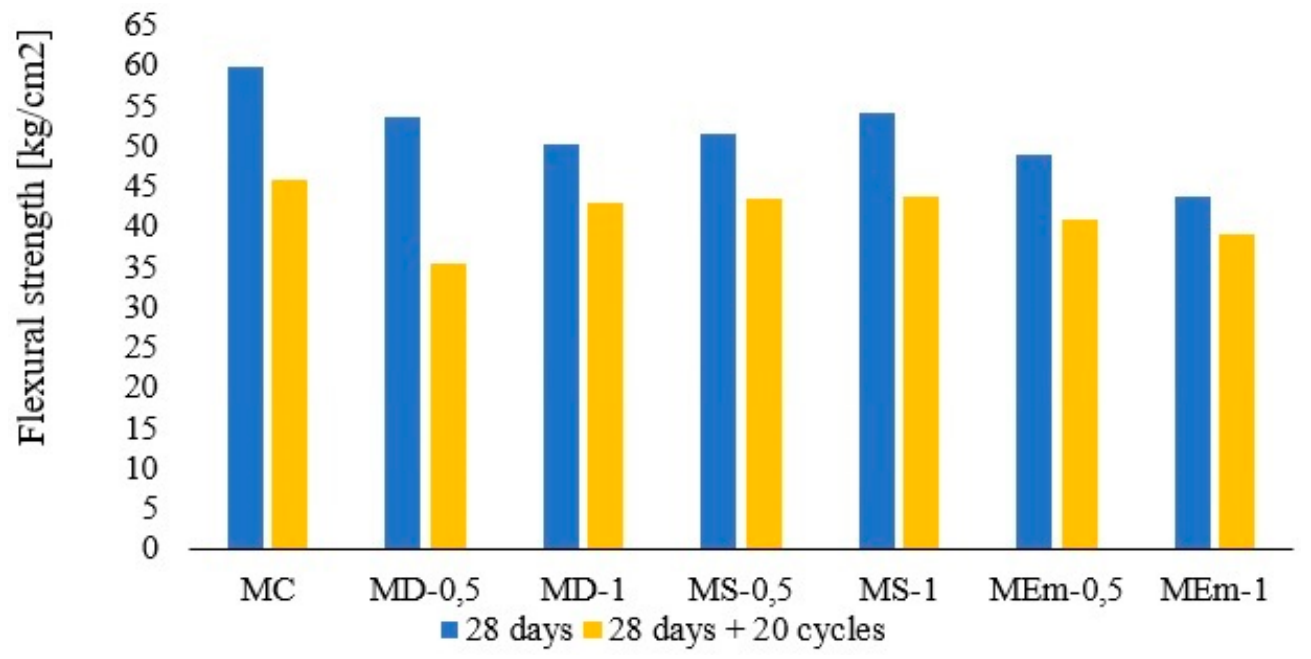

Figure 13. Cement mortar factorial results, flexural strength in aged samples.

Figure 13 shows that, in all cases, less flexural strength is obtained after applying the cycles. MD-0.5 is the most affected case with a 34\% reduction compared to the 28-day resistance. On the other hand, MEm-1 is the samples with the lowest strength reduction (12\%). However, it is not possible to associate the flexural strength reduction with the fibre addition. This is because the control sample shows as well a considerable reduction (23\%), after the application of the cycles. Furthermore, it is not possible to associate durability benefits to the paraffinic emulsion treatment.

Hence, considering the results presented in Figure 13 and the compressive strength ones showed by Figure 12, it is possible to conclude that adding fibres not necessarily affects the mixes durability. A possible explanation is the composition of the typical cements used in Chile, which are the ones incorporated in the present investigation. In effect, the typical Chilean cements are pozzolanic, being the pozzolana, a well know mitigating factor of potential degradation of natural fibres in the cementitious matrix. 
Stage 2 results indicate as well that treating fibres with paraffinic emulsion does not produce performance advantages. This can be related with the fact that paraffinic emulsion prevents a good fibre-cementitious matrix interaction. Therefore, application of the paraffinic emulsion is not considered in stage 3 . Finally, the incorporation of $0.5 \%$ fibre presented the most favourable results and, therefore, it is the percentage of fibre considered in stage 3 .

\subsection{Stage 3: Concrete Factorial}

\subsubsection{Fresh State Behaviour}

Table 8 shows the slump recorded using the Abrams cone method [67].

Table 8. Concrete factorial results, docility.

\begin{tabular}{cc}
\hline Concrete Mix & Slump (cm) \\
\hline CC & 7.0 \\
CD $-0,5$ & 7.0 \\
CS- 0,5 & 8.0 \\
\hline
\end{tabular}

The CS- 0.5 mix shows a slight increase in its docility. However, this value is within the range of permissible variation $[68,73]$, and thus it is not necessarily associated with the added fibre.

In contrast, the incorporation of dry fibre did not show variation with respect to the control sample.

\subsubsection{Compressive Strength}

The concrete compressive strength results are presented in Figure 14.

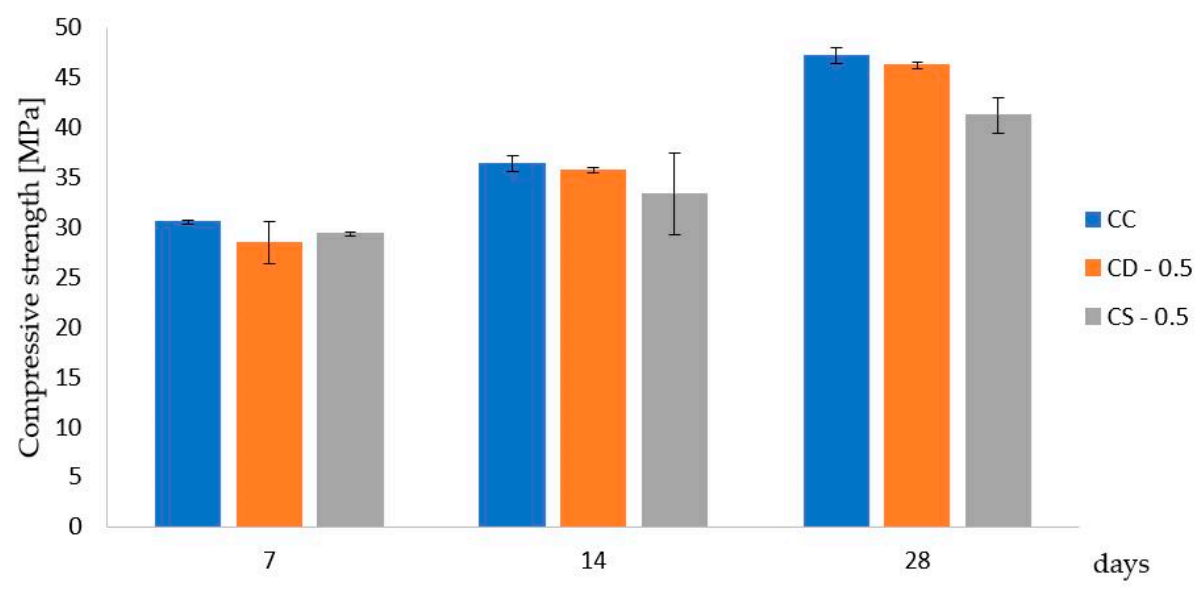

Figure 14. Concrete factorial results, compressive strength.

At all ages, the greatest strength is obtained by the control sample. However, the CD-0.5 sample has slightly lower values. In fact, after 28 days its strength only differs $0.98 \mathrm{MPa}$ of the control sample, being $0.82 \mathrm{MPa}$ the standard error. Hence, the difference is very close to the error. The CS- 0.5 sample reached a 28-day difference of $1.8 \mathrm{MPa}$ respect to the control sample strength.

The good results obtained can be explained in a similar way than the results of stage 2 described in Section 3.2.2.

Other researchers have also found their best compressive strength results with lower amount of natural fibres $[35,37,42,43]$. In general, the compressive strength decreases more, for similar percentage of fibre, than the results presented in this section. Actually, the compressive strength reductions of those investigations varies between $4.22 \%$ and $11.00 \%$ for $0.50 \%$ fibre reinforcement with respect to the weight of cement $[35,37,43]$. In the present investigation the best result differs only $2.00 \%$ of the control sample, being the difference very close to the standard error with a coefficient of variation $1.73 \%$. 
This is a very promising result towards developing practical alternatives for effectively reusing the bark fibres of Eucalyptus globulus species, considering that concrete strength, and particularly compressive strength, is related with the massive use of concrete and different numerous of concrete applications.

\subsubsection{Flexural Strength}

Figure 15 presents the results of the concrete flexural strength.

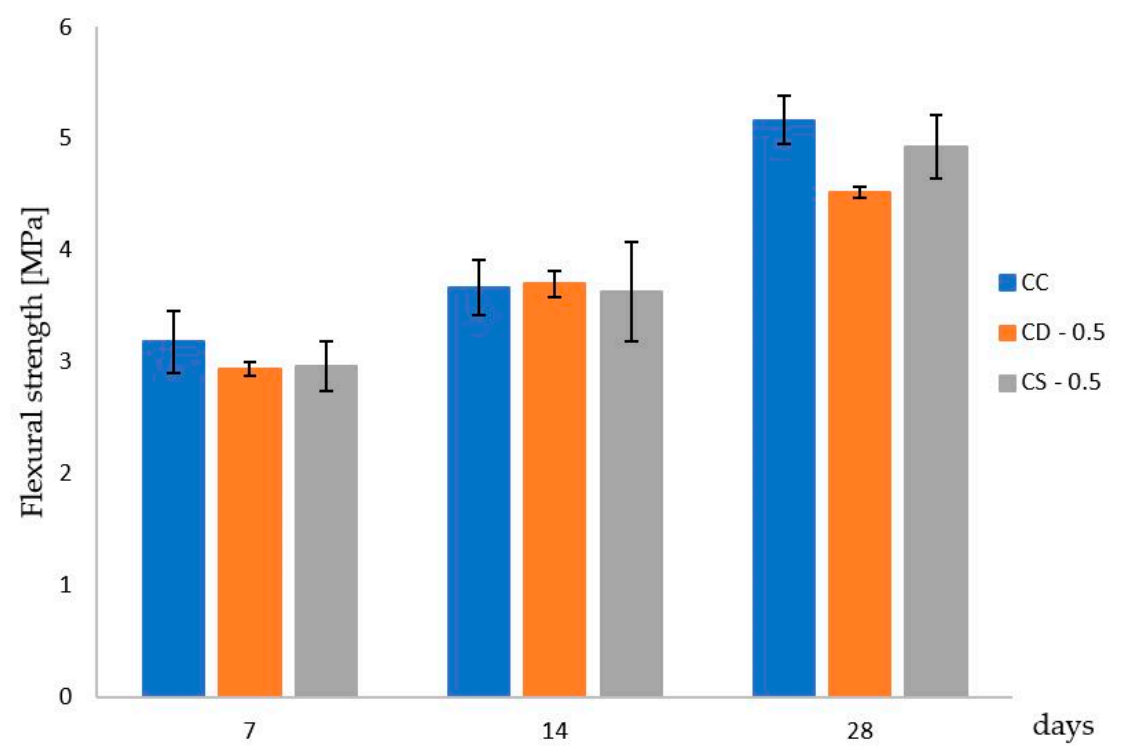

Figure 15. Concrete factorial results, flexural strength.

At 28 days, the best results are obtained by the control sample. It is observed that the CS- 0.5 sample has a $0.20 \mathrm{MPa}$ reduction, being $0.22 \mathrm{MPa}$ the standard error, i.e., the difference cannot be considered significant. The CD-0.5 sample shows a reduction of $0.7 \mathrm{MPa}(13 \%)$.

The good results obtained can be explained in a similar way than the results of stage 2 described in Section 3.2.3.

\section{Discussion}

The present article focuses on the mechanical properties traditionally evaluated in mortars and concrete, i.e., compressive and flexural strength.

The results presented indicate that mortars and concretes with $0.5 \%$ and $1.0 \%$ of bark fibre of E. globulus develop an acceptable behaviour, although lower when compared with samples without fibre. Nevertheless, when comparing the results with the ones obtained with other types of vegetable fibres $[35,37,43]$, it is observed that the strength reduction is low, particularly in the case of the reinforced concrete.

Although reports indicate that the incorporation of natural fibres can produce a significant reduction in concrete strength [42], which is not the case in this study. The explanation behind this phenomenon is related with the technical factors discussed in Section 3 and the fact that both concrete and fibre are geo-dependent materials, i.e., their characteristics and properties depend on a series of environmental and geographical factors influencing the materials properties. For example, availability of plant fibres more resistant to aggressive environments, such as those of high alkalinity. In this aspect, E. globulus bark fibres may be more resistant to these environments. In addition, Chilean most common cements are pozzolanic, being the pozzolana a well know mitigating factor of potential degradation of natural fibres in the cementitious matrix.

Geo-dependency is fundamental when dealing with waste materials and concrete, especially since the alternatives of solutions must be practical and possible to apply in order to effectively reuse 
the waste. Hence, they must be feasible not only from a technical point of view but also from an economic perspective including, for instance, transportation costs. Actually, geo-dependency is one of the characteristics of the concrete material that make it so popular, as it is possible to use local raw materials.

The promising results obtained in the phase of the investigation presented in this paper can contribute to reduce the waste material, for instance, at the Chilean forest industry, especially considering the massive use of concrete in Chile. In fact, it is estimated that over $70 \%$ of the Chilean constructions are built with this material [74]. Furthermore, concrete is the material of greater volume used by man and it is very difficult to replace in numerous infrastructure applications [75].

The present phase of the research was focused on the evaluation of traditional mechanical properties as compressive and flexural strength. However, considering the different potential benefits of incorporating fibres in the concrete material, it is planned to specifically evaluate other engineering properties in the coming research phases. Those engineering properties include the shrinkage cracking progression, tensional post-cracking behaviour, residual strength, energy dissipation, and ductility of the concrete reinforced with E. globulus bark fibres. In the specific case of ductility, although was not experimentally evaluated in this phase of the research, it was possible to visually observe that samples with fibres were clearly less brittle than the control ones, i.e., without bark fibre reinforcement.

Finally, it is important to highlight the importance of the present phase of the research. In effect, although fibres can improve different engineering properties of the concrete material (as the ones mentioned in the previous paragraph), if the strength of the composite concrete-fibre is significantly reduced regarding to the reference concrete, the possibilities to effectively reuse the waste are very limited. This is due to the fact that concrete strength is related with the massive use of this material in numerous different applications. Then, as the percentage of natural fibres possible to incorporate in the concrete material is low, the massiveness factor is fundamental to reuse significant amounts of waste natural fibres. In this respect, the present phase of the investigation has demonstrated that the incorporation of E. globulus bark fibre does not reduce significantly the compressive and flexural strength of the concrete material.

\section{Conclusions}

The work presented in this article is part of an ongoing project. However, at the present state, very valuable conclusions are possible to obtain regarding to the mechanical properties traditionally evaluated in cement mortars and concrete, i.e., compressive and flexural strength.

Considering that the incorporation of natural fibres can produce a significant concrete strength reduction, the most important findings of this study were the results obtained for the concrete compressive and flexural strength. In effect, there is only a slight strength reduction when $0.5 \%$ of E. globulus bark fibre (with respect to the cement weight) is included. Furthermore, one of the results indicate that the strength difference cannot be considered significant as the reduction is less than the standard error.

Those are very important results because concrete strength is a fundamental characteristic related with the massive use of this material. Actually, compressive strength is a typical property tested in real structures when they are being built. For certain structures, as pavements, the flexural strength is tested instead. In addition to the favourable results of strength, the consistency results of the optimal bark fibre proportions are also appropriate, which is important as well, because in real-world structures, workability is also tested. Moreover, workability is directly related with the process of concrete mixing, placing and compacting. Moreover, adequate mix consistency also means that the composite concrete-bark fibre can be applied with traditional construction equipment. Even more, natural fibres as bark fibres of E. globulus are not abrasive to the processing equipment as some man-made fibres.

Hence, the article presents optimal results and proportions to promote the practical use of bark fibre of E. globulus in numerous areas of concrete applications as, roadways, residential, agricultural, commercial, tunnelling, precast concrete products, airports, warehouses, waterways, elevated decks, 
structural reinforcement, and bridges, between others. Even more, the results exhibit that the inclusion of bark fibre of E. globulus not only does not reduce the concrete strength significantly, but even it is possible to obtain a compressive strength over $42 \mathrm{MPa}$, which would open the possibility to high strength concrete.

The inclusion of E. globulus bark fibre in the manufacture of mortars and concrete is a good alternative to counteract the problems associated with the use and disposal of this waste. Moreover, it contributes to minimize the environmental impact caused in the construction, for instance, by the production of man-made fibres. In effect, man-made fibres are non-bio-degradable, and when they are disposed of in landfills, they can cause pollution by releasing heavy metals and other pollutants into the ground water as well as in the soil. On the contrary, natural fibres are renewable, biodegradable, less expensive and locally abundant, many times as a waste, as it is the case of E. globulus bark fibre. Furthermore, the carbon footprints as well as the embodied energy of natural fibres are very low as compared to artificial ones. Therefore, from a sustainable perspective, the use of natural fibres in concrete are an important alternative to artificial fibres, using natural assets and with a non-hazardous impact on the environment. This is especially relevant in the construction industry which is responsible for a large amount of non-renewable resources and emission of carbon dioxide gases. Considering the favourable results obtained, the use of E. globulus bark fibre in concrete can be a relevant contribution to promote sustainable construction materials.

The results presented in this article are an interesting antecedent to consider the reinforcement of concrete with Eucalyptus bark fibre, especially in countries with important areas of Eucalyptus, such as Australia, Spain, Portugal, Kenya, Brazil, or Uruguay. However, to evaluate the mechanical properties of those barks into the concrete, specific research is necessary.

In fact, the work presented in this article, attempts to contribute to the research related with understanding the properties of concrete reinforced with Eucalyptus bark fibres and its possibilities as an eco-friendly construction alternative to the concrete reinforced with man-made fibres. In effect, although there are numerous investigations about natural fibres, there is a lack of research related with the use of bark fibres of the E. globulus species in the concrete material. This is relevant because bark can be different between trees and even among Eucalyptus species.

Author Contributions: Conceptualization, M.P., C.M., and C.F.; methodology, M.P., C.F., and C.M.; formal analysis, C.M., M.P., and C.F.; writing, C.M., A.C.; writing-review and editing, M.P. All authors have read and agreed to the published version of the manuscript.

Funding: This research was funded by ANID PIA/Apoyo CCTE AFB170007.

Conflicts of Interest: The authors declare no conflict of interest.

\section{References}

1. Monteiro, P.J.; Miller, S.A.; Horvath, A. Towards sustainable concrete. Nat. Mater. 2017, 16, 698-699. [CrossRef]

2. Torgal, F.P.; Jalali, S. Natural fiber reinforced concrete. In Fibrous and Composite Materials for Civil Engineering Applications; Woodhead Publishing: Cambridge, UK, 2011; pp. 154-167.

3. Afroughsabet, V.; Biolzi, L.; Ozbakkaloglu, T. High-performance fiber-reinforced concrete: A review. J. Mater. Sci. 2016, 51, 6517-6551. [CrossRef]

4. de Souza Castoldi, R.; de Souza, L.M.S.; de Andrade Silva, F. Comparative study on the mechanical behavior and durability of polypropylene and sisal fiber reinforced concretes. Constr. Build. Mater. 2018, 211, 617-628. [CrossRef]

5. ACI. Measurement of Properties of Fiber Reinforced Concrete; ACI 544.2R-89; American Concrete Institute: Farmington Hills, MI, USA, 2009.

6. Krishna, N.K.; Prasanth, M.; Gowtham, R.; Karthic, S.; Mini, K.M. Enhancement of properties of concrete using natural fibers. Mater. Today Proc. 2018, 5, 23816-23823. [CrossRef]

7. Saravanan, N.; Buvaneshwari, M. Experimental Investigation on Behaviour of Natural Fibre Concrete (Sisal Fibre). Cellulose 2018, 54, 66. 
8. Wei, J.; Meyer, C. Improving degradation resistance of sisal fiber in concrete through fiber surface treatment. Appl. Surf. Sci. 2014, 289, 511-523. [CrossRef]

9. Chalioris, C.E.; Kosmidou, P.M.K.; Karayannis, C.G. Cyclic response of steel fiber reinforced concrete slender beams: An experimental study. Materials 2019, 12, 1398. [CrossRef] [PubMed]

10. Kytinou, V.K.; Chalioris, C.E.; Karayannis, C.G.; Elenas, A. Effect of Steel Fibers on the Hysteretic Performance of Concrete Beams with Steel Reinforcement-Tests and Analysis. Materials 2020, 13, 2923. [CrossRef]

11. Guerini, V.; Conforti, A.; Plizzari, G.; Kawashima, S. Influence of Steel and Macro-Synthetic Fibers on Concrete Properties. Fibers 2018, 6, 47. [CrossRef]

12. Alabduljabbar, H.; Alyousef, R.; Alrshoudi, F.; Alaskar, A.; Fathi, A.; Mustafa Mohamed, A. Mechanical Effect of Steel Fiber on the Cement Replacement Materials of Self-Compacting Concrete. Fibers 2019, 7, 36. [CrossRef]

13. Kytinou, V.K.; Chalioris, C.E.; Karayannis, C.G. Analysis of Residual Flexural Stiffness of Steel Fiber-Reinforced Concrete Beams with Steel Reinforcement. Materials 2020, 13, 2698. [CrossRef] [PubMed]

14. Yoo, D.Y.; Banthia, N. Impact resistance of fiber-reinforced concrete-A review. Cem. Concr. Comp. 2019, 104, 103389. [CrossRef]

15. Pacheco-Torgal, F.; Jalali, S. Cementitious building materials reinforced with vegetable fibres: A review. Constr. Build. Mater. 2011, 25, 575-581. [CrossRef]

16. Behbahani, H.P.; Nematollahi, B.; Farasatpour, M. Steel Fiber Reinforced Concrete: A Review. In Proceedings of the International Conference on Structural Engineering Construction and Management (ICSECM2011), Kandy, SriLanka, 15-17 December 2011.

17. ASTM. ASTM C1116/C1116M-10a. Standard Specification for Fiber-Reinforced Concrete; ASTM: West Conshohocken, PA, USA, 2015.

18. ACI Committee 544 (Fiber Reinforced Concrete). State of the Art Report on Fiber Reinforced Concrete; ACI 544.1R: Farmington Hills, MI, USA, 2002.

19. Islam, M.S.; Ahmed, S.J. Influence of jute fiber on concrete properties. Constr. Build. Mater. 2018, 189, 768-776. [CrossRef]

20. Torgal, F.P.; Fucic, A.; Jalali, S. Toxicity of Building Materials; Woodhead Publishing: Cambridge, UK, 2012.

21. Pacheco-Torgal, F.; Labrincha, J.A. The future of construction materials research and the seventh UN Millennium Development Goal: A few insights. Constr. Build. Mater. 2013, 40, 729-737. [CrossRef]

22. Machaka, M.M.; Basha, H.S.; ElKordi, A.M. The Effect of Using Fan Palm Natural Fibers on the Mechanical Properties and Durability of Concrete. Inter. J. Mater. Sci. Eng. 2014, 2, 76-80. [CrossRef]

23. Kundu, S.P.; Chakraborty, S.; Roy, A.; Adhikari, B.; Majumder, S.B. Chemically modified jute fibre reinforced non-pressure (NP) concrete pipes with improved mechanical properties. Constr. Build. Mater. 2012, 37, 841-850. [CrossRef]

24. Awwad, E.; Mabsout, M.; Hamad, B.; Farran, M.T.; Khatib, H. Studies on fiber-reinforced concrete using industrial hemp fibers. Constr. Build. Mater. 2012, 35, 710-717. [CrossRef]

25. Patel, D.; Patel, V.M. Application of sugarcane bagasse fibres as concrete composites for rigid pavement. Indian J. Res. 2015, 4, 4-5.

26. Reis, J.M.L. Sisal fiber polymer mortar composites: Introductory fracture mechanics approach. Constr. Build. Mater. 2012, 37, 177-180. [CrossRef]

27. Fidelis, M.E.A.; Pereira, T.V.C.; Gomes, O.D.F.M.; de Andrade Silva, F.; Toledo Filho, R.D. The effect of fiber morphology on the tensile strength of natural fibers. J. Mater. Res. Technol. 2013, 2, 149-157. [CrossRef]

28. Andiç-Çakir, Ö.; Sarikanat, M.; Tüfekçi, H.B.; Demirci, C.; Erdoğan, Ü.H. Physical and mechanical properties of randomly oriented coir fiber-cementitious composites. Compos. B Eng. 2014, 61, 49-54. [CrossRef]

29. Ardanuy, M.; Claramunt, J.; Toledo Filho, R.D. Cellulosic fiber reinforced cement-based composites: A review of recent research. Constr. Build. Mater. 2015, 79, 115-128. [CrossRef]

30. Balasubramanian, J.C.; Selvan, S.S. Experimental investigation of natural fibre reinforced concrete in construction industry. Inter. Res. J. Eng. Technol. 2015, 2, 179.

31. Meredith, J.; Ebsworth, R.; Coles, S.R.; Wood, B.M.; Kirwan, K. Natural fibre composite energy absorption structures. Compos. Sci. Technol. 2012, 72, 211-217.

32. Ansell, M. Natural Fibre Composites \& Their Role in Engineering. Available online: http://staff.bath.ac.uk/mssmpa/ index/PAPERS\%20\&\%20PRESENTATIONS/Ansell\%20natural\%20fibres\%20BRE\%20Sept\%2011.pdf (accessed on 23 September 2011). 
33. Srivastava, V.; Mehta, P.K.; Nath, S. Natural fiber in cement and concrete matrices-A review. J. Environ. Nanotechnol. 2013, 2, 63-66. [CrossRef]

34. Yan, L.; Kasal, B.; Huang, L. A review of recent research on the use of cellulosic fibres, their fibre fabric reinforced cementitious, geo-polymer and polymer composites in civil engineering. Compos. B Eng. 2016, 92, 94-132. [CrossRef]

35. Zakaria, M.; Ahmed, M.; Hoque, M.M.; Islam, S. Scope of using jute fiber for the reinforcement of concrete material. Text. Cloth. Sustain. 2017, 2, 11. [CrossRef]

36. Soto, I.I.; Ramalho, M.A.; Izquierdo, O.S. Post-cracking behavior of blocks, prisms, and small concrete walls reinforced with plant fiber. Rev. IBRACON Estrut. Mater. 2013, 6, 598-612. [CrossRef]

37. Okeola, A.A.; Abuodha, S.O.; Mwero, J. The effect of specimen shape on the mechanical properties of sisal fiber-reinforced Concrete. Open Civ. Eng. J. 2018, 12, 368-382. [CrossRef]

38. Bertelsen, I.M.G.; Ottosen, L.M.; Fischer, G. Influence of fibre characteristics on plastic shrinkage cracking in cement-based materials: A review. Constr. Build. Mater. 2020, 230, 116769. [CrossRef]

39. Llerena Encalada, A. Estudio de Compuestos Cementíceos Reforzados con Fibras Vegetales: Evaluaci ón Previa del Comportamiento de un Panel de Cemento Blanco con Adición de Meta-Caolín Reforzado con un Textil No-Tejido de Fibras Largas de lino y Cáñamo. Master's Thesis, Universitat Politècnica de Catalunya, Cataluya, Spain, 2014. (In Spanish).

40. Sen, T.; Reddy, H.N. Green retrofitting of reinforced concrete beams employing sustainable natural sisal fibre composites as alternative to artificial fibre composites for enhanced shear strength. EEMJ 2019, 18, 1379-1390. [CrossRef]

41. Ribeiro, B.; Uchiyama, T.; Tomiyama, J.; Yamamoto, T.; Yamashiki, Y. Development of Interlocking Concrete Blocks with Added Sugarcane Residues. Fibers 2020, 8, 61. [CrossRef]

42. Pehanich, J.; Blankenhorn, P.; Silsbee, M. Wood fibre surface treatment level effects on selected mechanical properties of wood fibre-cement composites. Cem. Concr. Res. 2004, 34, 59-65. [CrossRef]

43. Yalley, P.P.; Kwan, A.S.K. Use of coconut fibre as an enhancement of concrete. J. Eng. Technol. 2009, 3, 54-73.

44. Yusra, A.; Triwulan, T.; Safriani, M.; Ikhsan, M. Use of bamboo fiber on the relationship between compressive strength and split tensile strength of high strength concrete. In Proceedings of the 2nd Aceh International Symposium on Civil Engineering, Banda Aceh, Aceh Province, Indonesia, 18-19 September 2020.

45. Quintero, S.; González, L. Uso de Fibra de Estopa de Coco para Mejorar las Propiedades Mecánicas del Concreto. Ing. Desarro. 2006, 20, 134-150. (In Spanish)

46. Osorio, J.; Varón, F.; Herrera, J. Comportamiento Mecánico del Concreto Reforzado con Fibras de Bagazo de Caña de Azúcar. DYNA 2007, 74, 69-79. (In Spanish)

47. Espinoza, M.J. Comportamiento Mecánico del Concreto Reforzado con Fibras de Bagazo de caña de Azúcar. Master's Thesis, Universidad de Cuenca, Cuenca, Ecuador, 2015. (In Spanish).

48. Uday, V.; Ajitha, B. Concrete reinforced with coconut fibres. IJESC 2017, 7, 10436-10439.

49. Tonoli, G.H.D.; Savastano Jr., H.; Fuente, E.; Negro, C.; Blanco, A.; Lahr, F.R. Eucalyptus pulp fibres as alternative reinforcement to engineered cement-based composites. Ind. Crop. Prod. 2010, 31, 225-232. [CrossRef]

50. Bown, H.E.; Lasserre, J.P. An air-drying model for piled logs of Eucalyptus globulus and Eucalyptus nitens in Chile. N. Z. J. Forestry Sci. 2015, 45, 17. [CrossRef]

51. INFOR. Anuario Forestal 2019; Instituto Forestal: Santiago, Chile, 2019. (In Spanish)

52. Geldres, E.; Gerding, V.; Schlatter, J.E. Biomasa de Eucalyptus nitens de 4-7 años de edad en un rodal de la X Región, Chile. Bosque 2006, 27, 223-230. (In Spanish) [CrossRef]

53. Ferreira, V.; Boyero, L.; Calvo, C.; Correa, F.; Figueroa, R.; Gonçalves, J.F.; Goyenola, G.; Graça, M.A.; Hepp, L.U.; Kariuki, S.; et al. A global assessment of the effects of eucalyptus plantations on stream ecosystem functioning. Ecosystems 2019, 22, 629-642. [CrossRef]

54. Becerra, C.F.; Montory, J.S.; Vega-Lara, J.; Norambuena-Contreras, J. New Biobased Composite Material Using Bark Fibres Eucalyptus. In Proceedings of the 13th Pacific Rim Bio-Based Composite Symposium Bio-Based Composites for a Sustainable Future, Concepción, Chile, 13-15 November 2016.

55. Ede, A.N.; Agbede, J.O. Use of coconut husk fiber for improved compressive and flexural strength of concrete. Inter. J. Sci. Eng. Res. 2015, 6, 968-974. 
56. Majada, J.; Lopez, A.; Oliveira, L.; Carvalho, A. Eucalyptus globulus Labill. In Producción y Manejo de Semillas y Plantas Forestales; Pemán, J., Navarro, R., Nicolás, J.L., Aránzazu, M., Serrada, R., Eds.; Ministerio de Agricultura, Alimentación y Medio Ambiente: Madrid, Spain, 2012; pp. 462-491.

57. Wei, J.; Meyer, C. Degradation mechanisms of natural fiber in the matrix of cement composites. Cem. Concr. Res. 2015, 73, 1-16. [CrossRef]

58. Onuaguluchi, O.; Banthia, N. Plant-based natural fibre reinforced cement composites: A review. Cem. Concr. Compos. 2016, 68, 96-108. [CrossRef]

59. Merta, I.; Tschegg, E.K. Fracture energy of natural fibre reinforced concrete. Constr. Build. Mater. 2013, 40, 991-997. [CrossRef]

60. INN. Cemento-Terminología, Clasificación y Especificaciones Generales. NCh148.Of68; Instituto Nacional de Normalización: Santiago, Chile, 1968. (In Spanish)

61. Chilean Highway Agency. Manual de Carreteras; Ministerio de Obras Públicas: Santiago, Chile, 2018. (In Spanish)

62. Réunion Internationale des Laboratoires d'Essais et de Recherches Sur Les Matériaux et Les Construction (RILEM). RILEM Technical Recommendations for the Testing and Use of Construction Materials, 1st ed.; CRC Press: London, UK, 1994.

63. INN. Determinación de la Consistencia-Parte 3: Método del Asentamiento del cono. NCh2257/3.Of96; Instituto de Nacional de Normalización: Santiago, Chile, 1996. (In Spanish)

64. ASTM C270. Standard Specification for Mortar for Unit Mansonry; American Society for Testing Materials: West Conshohocken, PA, USA, 2015.

65. Junco, C. Morteros Aligerados con Residuos de Espumas Rígidas de Poliuretano Obtención, Caracterización y Puesta en obra. Ph.D. Thesis, Universidad de Burgos, Burgos, España, 2012. (In Spanish).

66. AENOR. Métodos de ensayo para piedra natural. In Determinación de la Resistencia al Envejecimiento Por Choque Térmico (UNE-EN-14066); Asociación Española de Normalización: Madrid, Spain, 2014.

67. ASTM C143. Standard Test Method for Slump of Hydraulic-Cement Concrete; American Society for Testing Materials: West Conshohocken, PA, USA, 2015.

68. ASTM C94/C94M. Standard Specification for Ready-Mixed Concrete; American Society for Testing Materials: West Conshohocken, PA, USA, 2015.

69. Egaña, Z. Manual del Mortero; ICH: Santiago, Chile, 1988. (In Spanish)

70. ACI. Standard Practice for Selecting Proportions for Normal, Heavyweight, and Mass Concrete; ACI 211.1-91; American Concrete Institute: Farmington Hills, MI, USA, 2002.

71. Momoh, E.O.; Osofero, A.I. Behaviour of oil palm broom fibres (OPBF) reinforced concrete. Constr. Build. Mater. 2019, 221, 745-761. [CrossRef]

72. INN. Morteros-Determinación de la Consistencia Medida En Obra. NCh2258.c94; Instituto Nacional de Normalización: Santiago, Chile, 1994. (In Spanish)

73. INN. Hormigón-Requisitos Generales. NCh170.2006; Instituto de Normalización Nacional: Santiago, Chile, 2006.

74. Davalos, A. Hormigón sustentable una nueva mirada a los materiales de construcción. Beauchef Mag. 2013, 5, 19-22.

75. Flatt, R.J.; Roussel, N.; Cheeseman, C.R. Concrete: An eco material that needs to be improved. J. Eur. Ceram. Soc. 2012, 32, 2787-2798. [CrossRef]

Publisher's Note: MDPI stays neutral with regard to jurisdictional claims in published maps and institutional affiliations.

(C) 2020 by the authors. Licensee MDPI, Basel, Switzerland. This article is an open access article distributed under the terms and conditions of the Creative Commons Attribution (CC BY) license (http://creativecommons.org/licenses/by/4.0/). 